\title{
(อ) OPEN ACCESS \\ Modern approach to the treatment of dry eye, a complex multifactorial disease: a P.I.C.A.S.S.O. board review
}

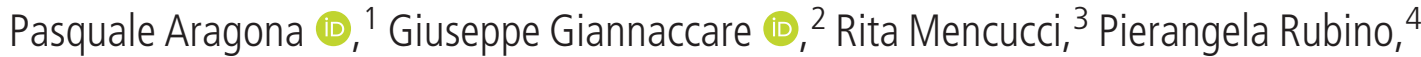 \\ Emilia Cantera, ${ }^{5}$ Maurizio Rolando (10 6
}

'Department of Biomedical Sciences, Ophthalmology Clinic, University of Messina, Messina, Italy

${ }^{2}$ Ophthalmology, Magna Graecia University of Catanzaro, Catanzaro, Italy

${ }^{3}$ Institute of Ophthalmology, Florence, Italy

${ }^{4}$ Ophthalmology, University of Parma, Parma, Italy

${ }^{5}$ Ophthalmology, Israelitic Hospital, Rome, Italy

${ }^{6}$ Ocular Surface Unit, ISPRE, Genoa, Italy

\section{Correspondence to}

Maurizio Rolando, Ocular Surface Unit, ISPRE Genova, Genoa, Italy;

maurizio.rolando@gmail.com

Received 18 December 2019 Revised 18 March 2020 Accepted 1 June 2020 Published Online First 23 July 2020

\section{ABSTRACT}

Dry eye disease (DED) is a growing public health concern affecting quality of life and visual function, with a significant socio-economic impact. It is characterised by the loss of homoeostasis, resulting in tear film instability, hyperosmolarity and inflammation of the ocular surface. If the innate immune response is unable to cope with internal bodily or environmental adverse conditions, the persistent, self-maintaining vicious circle of inflammation leads to the chronic form of the disease. Treatment of DED should be aimed at the restoration of the homoeostasis of the ocular surface system. A proper diagnostic approach is fundamental to define the relevance and importance of each of the DED main pathogenic factors, namely tear film instability, epithelial damage and inflammation.

Consideration also needs to be given concerning two other pathogenic elements: lid margin changes and nerve damage. All the factors that maintain the vicious circle of DED in the patient's clinical presentation have to be considered and possibly treated simultaneously. The treatment should be long-lasting and personalised since it has to be adapted to the different clinical conditions observed along the course of the disease. Since DED treatment is frequently unable to provide fast and complete relief from symptoms, empathy with patients and willingness to explain to them the natural history of the disease are mandatory to improve patients' compliance. Furthermore, patients should be instructed about the possible need to increase the frequency and/or change the type of treatment according to the fluctuation of symptoms, following a preplanned rescue regimen.

\section{INTRODUCTION}

Dry eye disease (DED) is a common ocular condition with a prevalence ranging between 5\% and $50 \%$ in the adult population. ${ }^{1}$ It is a disabling disorder affecting both visual function and quality of life, and has a significant socioeconomic impact. The disease is characterised by the loss of homoeostasis of the ocular surface, which results in tear film instability, hyperosmolarity and inflammation of the ocular surface. ${ }^{2-5}$ A report by van Setten et al has suggested a link between seasonal environmental conditions and DED. In that study, almost half of responders stated that seasonal weather conditions had a significant impact on their symptoms, most notably wind and sunshine, whereas the summer and the winter were most commonly associated with dry eye complaints. ${ }^{6}$ Other factors that may contribute to the development or worsening of DED include contact lens wear. $^{78}$
In a recent publication, a dry eye Experts Board presented a simple, time-saving flow chart, including a point-by-point explanatory guide, to better define the diagnosis of DED, in what was defined as a threestep method. To summarise, the three-step method was described as follows: the first step consisted in asking about symptoms with a questionnaire; the second step in observing the ocular surface at the slit lamp in order to study the tear film, the staining of the ocular surface for epithelial damage and lid conditions; the third step in addressing tear clearance and corneal sensitivity. ${ }^{9}$ In this article, we address the management of the patients once the dry eye diagnosis has been made. Based on the existing literature and on a consensus among the members of our study group, the opportunity of a dynamic therapeutic strategy according to the clinical results obtained during the course of the disease, is suggested. In this article, we wish to focus on the treatment necessary to obtain an improvement of the ocular surface conditions and a long-term control of the disease.

Taking into account the medical history and presence of possible risk factors, the authors proposed a more personalised, clinical assessment that could be achieved by considering the three pathogenic factors, which are always present at different levels of expression. These pathogenic factors are (1) tear film instability, (2) epithelial malfunction and damage and (3) more or less clinically evident inflammation. These factors can be exacerbated by other two pathogenic findings: lid margin changes and nerve damage (figure 1$)^{26}$

In general, the treatment of DED should be aimed at re-establishing and maintaining the ocular surface system homoeostasis that was disrupted as a consequence of the vicious circle of the disease. ${ }^{10}$

\section{PATHOGENIC FACTORS OF DED}

Tear film instability is a hallmark of DED and is caused by changes in lipid layer function and in quantity, quality, and availability of tear fluid. It is an important source of symptoms and, possibly, one of the main sources of anatomical and functional changes of epithelia and, hence, a starting point for inflammation. ${ }^{11}$ Another important factor is the function of transmembrane and secretory mucins, which facilitate the contact between tear fluid and epithelial cells, adversely affected by tear film instability. $^{12-14}$

Epithelial malfunction caused by friction, adverse environmental factors, ocular surface irritation and/ 


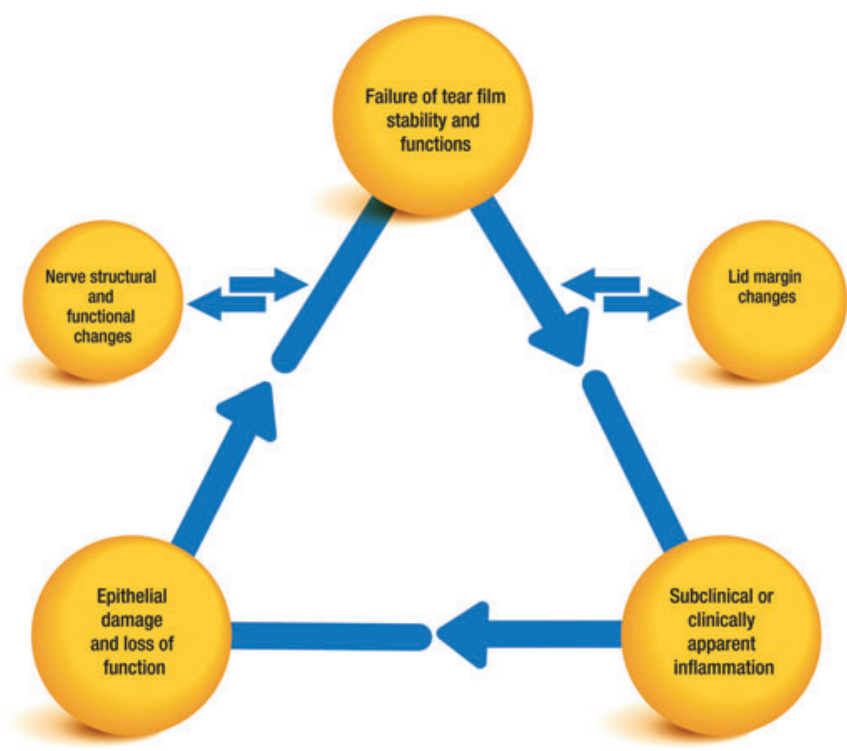

Figure 1 Key pathogenic factors contributing to the vicious circle of dry eye disease. Modified from Aragona and Rolando. ${ }^{26}$

or nerve impairment can lead to a further injury. This plays a key role in the continued tear film instability, the increasing inflammatory reaction and the reduced protection of nerve endings. ${ }^{15}$ The initial inflammatory reaction on the ocular surface results from innate immunological processes, involving the epithelial response to external stimuli, mediated by the activation of tolllike receptors and the related cascade of events. ${ }^{16-25}$ A strong and/or prolonged exposure to an inflammation-provoking stimulus may lead to an immunologic adaptive reaction, responsible for the chronic form of the disease.

The thickening and rounding of the lid margins, causing a reduced congruity with the eye bulb as well as the presence of eyelid notches, can affect the shape and function of the menisci. So the tear film distribution and the lipid layers spreading will be adversely affected. Impairment or malfunction of the lidassociated glands greatly influence the qualitative and/or quantitative composition of tear lipids, and are a possible source of inflammation and infection. Nerve function impairment and anatomical changes will affect both epithelial viability and turnover, in addition to tear film production. However, the role of nerve function in maintaining ocular surface homoeostasis and inducing the inflammatory response has yet to be elucidated.

\section{DIAGNOSIS AND ASSESSMENT OF DED}

At present, the cause of dysfunction can be difficult to be determined due to the number of potential factors already discussed, which makes an aetiological approach to treatment difficult to pursue. It is therefore of critical importance that a proper diagnostic approach determines the relevance of each of these factors in the patient's clinical presentation, so that an effective, long-lasting and personalised treatment can be administered and modified if necessary. ${ }^{26}$ All the factors, which contribute to and maintain the vicious circle of the disease, have to be considered and potentially treated simultaneously. Therefore, establishing the role played by each of them in the clinical picture represents the basis of the therapeutic strategy. This allows the identification of the key factor(s) of DED in the single patient, which can be subsequently targeted while also taking into account other alterations. If there are two or more factors, a multiple strategy can

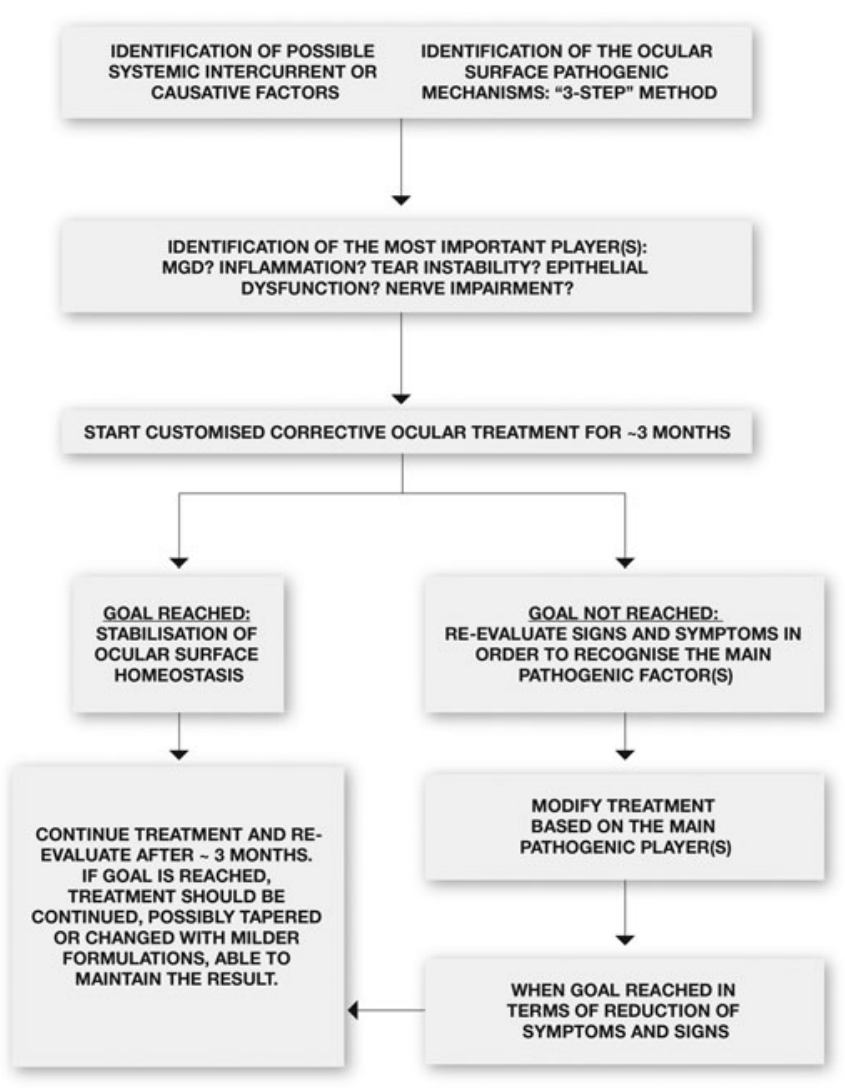

Figure 2 Dry eye disease management algorithm.

be used. Furthermore, the most active factor can be selected and addressed first and/or more aggressively (figure 2).

For example, if significant inflammation of the meibomian glands (MGs) is present, stabilising the tear film without correcting the lid inflammation will be ineffective. In fact, $\mathrm{MG}$ changes will cause a disruption of the lipid layer stability, resulting in a reduced tear film break-up time and an inflammatory response in the conjunctival epithelium. Therefore, the main goal should be to reduce lid margin inflammation. This will include lid margin hygiene, corticosteroids/antibiotic ointment and eye drops, together with the use of tear substitutes in order to allow a more efficient control of the tear film stability. The choice of the tear substitute is also an important factor to consider: in this example, a low-viscosity formulation with limited retention time, thus able to dilute the proinflammatory agents present on the ocular surface and to increase tear clearance would be recommended. ${ }^{27-29}$ The use of punctal plugs, even in the presence of poor tear volumes, should be avoided, as good clearance of the pro-inflammatory tear fluid is mandatory, together with efficient lid hygiene. However, a recent paper has demonstrated that the increase of tear inflammatory cytokine levels in patients with DED, treated with punctal plugs was temporary and returned to baseline after 3 weeks. ${ }^{30}$ Once lid margin inflammation is under control, the therapeutic strategy can be changed to address tear film instability and volume as well as epithelial protection, in order to further decrease inflammation. The addition of more viscous tear substitutes with osmo-protective activity can be used in conjunction with milder steroid eye drops. Punctal plugs, if still needed, could be taken into consideration, at this point, as a further tool. 
Once a clinical improvement is achieved, a continued lid hygiene programme, including appropriate tear substitutes to prevent recurrence of the acute disease, would be mandatory. Timing of controls would be based on the presumed efficacy of the treatment used (table 1).

At the same time, the patient should be informed about the aim of the prescribed therapy that it could be changed based on the clinical results and that the treatment effect may take some time to manifest.

\section{TREATING SYMPTOMS AND SIGNS}

Diagnosis and subsequent treatment of DED can be extremely challenging due to a lack of a single clinical assessment and the wide variation in symptoms. In addition, patient-reported symptoms frequently do not correspond to observed changes in clinical signs. $^{5253}$ Tear substitutes have been traditionally used for the treatment of DED to improve symptoms. However, it is important to note that tear substitutes are not specifically designed to improve symptoms, but to prevent their build-up. Consequently, they should be instilled regularly throughout the day to avoid symptom aggravation and not used on an as-needed basis. It is also important to consider that some eye drop formulations may contain preservatives, which have the potential to adversely affect the ocular surface and induce noxious symptoms. In these situations, it is important to limit their long-term use.

To increase tear film stability, polymers such as hyaluronic acid have been suggested for use. These polymers allow the correction of the tear film volume and improve its functional characteristics by increasing the tear film volume, ocular surface wettability and fluid spreading. Recently, a new generation of multiple-action tear substitutes, made of a combination of polymers with different characteristics, was put on the market. ${ }^{29}$

\section{Management of inflammation}

Control of inflammation is considered mandatory in order to improve symptomatology. Direct inflammatory damage or lack of epithelial protection can make free nerve endings of the corneal epithelium more sensitive to normal and environmental stimuli, inducing neuropathic pain, a typical symptom of DED. ${ }^{54}$ However, the ability to immediately treat these symptoms is poor, which frequently leads to non-compliance due to lack of prompt effectiveness. Contact lenses (both scleral and silicone-hydrogel) as well as blood-derived eye drops have been suggested as possible treatments for this condition. ${ }^{51} 55-59$ Another systemic approach addressing the central nervous system with gamma-aminobutyric acid (GABA)-mimetic substances, used for peripheral pain, has also been suggested. ${ }^{60}$

The control and reduction of ocular surface inflammation, which may derive from epithelial damage and environmental stressors, is another key component of any treatment regimen. Corticosteroids are typically used in the treatment of ocular surface inflammation, ${ }^{31-33}$ particularly milder corticosteroids such as those naturally produced by the ocular surface epithelium. Cortisol (called hydrocortisone, when used as a drug), which can be produced at the ocular surface by epithelial cells under certain physiological conditions, contributes to the regulation of inflammatory processes ordinarily occurring and acts as a protective mechanism against environmental antigens. ${ }^{61}{ }^{62}$ Inflammation is an important contributor to the vicious circle of DED and is frequently the factor that causes the disease to become chronic. Therefore, controlling inflammation is fundamental to prevent and treat chronic DED. ${ }^{63-66}$ Evidence suggests that long-term inflammation in DED elicits morphological and functional changes, which can lead to a change in the expression profile of inflammatory cytokines (interleukin (IL)-1a, IL-1 $\beta$, IL-6, IL-17,

\begin{tabular}{|c|c|c|c|}
\hline$\sim$ Month 1 & $\sim$ Month 2 & \multicolumn{2}{|l|}{$\sim$ Month 3} \\
\hline \multicolumn{4}{|c|}{ Tx for dry eye and inflammation } \\
\hline Lid hygiene (at home) & \multicolumn{3}{|l|}{ Warm/hot compresses + medicated wipes (two times per day) } \\
\hline Anti-inflammatory & \multicolumn{3}{|l|}{ Mild corticosteroids for 2 weeks } \\
\hline Tear substitutes & \multicolumn{3}{|c|}{$\begin{array}{l}\text { Use fluid tear substitutes two to four times a day in order to restore tear film stability (ie, semifluorinated alkane eye drops) and break DE vicious } \\
\text { circle (ie, sodium hyaluronate/trehalose, other MATS) }\end{array}$} \\
\hline \multicolumn{4}{|c|}{ Tx for MGD with blepharitis } \\
\hline Lid hygiene (at home) & \multicolumn{3}{|l|}{ Warm/hot compresses + medicated wipes (two times per day) } \\
\hline Anti-inflammatory & $\begin{array}{l}\text { Potent corticosteroids at decreasing doses + other anti- } \\
\text { inflammatory molecules (ie, omega3 supplementation) }\end{array}$ & $\begin{array}{l}\text { Milder corticosteroids at decreasing } \\
\text { doses; continue other anti-inflammatory } \\
\text { molecules (ie, omega3 supplementation) }\end{array}$ & $\begin{array}{l}\text { Stop corticosteroids; continue other } \\
\text { anti-inflammatory molecules (ie, } \\
\text { omega3 supplementation) }\end{array}$ \\
\hline Antibiotics & $\begin{array}{l}\text { Treat with courses of ointments based on drugs with anti- } \\
\text { inflammatory activity once daily or two times per day (ie, } \\
20 \text { days with tetracyclines, macrolides, fluoroquinolones) }\end{array}$ & $\begin{array}{l}\text { Reduce ointment application: once daily } \\
\text { for } 10 \text { days }\end{array}$ & $\begin{array}{l}\text { Continue ointment application: once } \\
\text { daily for } 10 \text { days }\end{array}$ \\
\hline Tear substitutes & \multicolumn{3}{|c|}{$\begin{array}{l}\text { Use fluid tear substitutes five to six times a day in order to favour tear film dilution and clearance (based on low viscosity formulations of sodium } \\
\text { hyaluronate) }\end{array}$} \\
\hline \multicolumn{4}{|c|}{$\begin{array}{l}\text { Tx for dry eye with severe } \\
\text { epithelial damage }\end{array}$} \\
\hline Lid hygiene (at home) & \multicolumn{3}{|l|}{ Warm/hot compresses + medicated wipes (two times per day) } \\
\hline Anti-inflammatory & $\begin{array}{l}\text { Potent corticosteroids at decreasing doses + cyclosporine } \\
\text { once daily }\end{array}$ & $\begin{array}{l}\text { Milder corticosteroids at decreasing doses } \\
+ \text { cyclosporine once daily }\end{array}$ & $\begin{array}{l}\text { Stop corticosteroids; cyclosporine } \\
\text { once daily }\end{array}$ \\
\hline Antibiotics & Systemic doxycycline $100 \mathrm{mg}$ two times per day & Systemic doxycycline $100 \mathrm{mg}$ once daily & $\begin{array}{l}\text { Stop doxycycline (consider to continue } \\
\text { its use, at lower concentrations that is, } \\
40 \mathrm{mg} / \text { day if necessary) }\end{array}$ \\
\hline Tear substitutes & \multicolumn{3}{|c|}{$\begin{array}{l}\text { High-mean viscosity (sodium hyaluronate, linear or cross-linked; other polymers) + molecules helping epithelial healing (vitamins, antioxidants } \\
\text { and bioprotectors) one drop five to six times a day }\end{array}$} \\
\hline
\end{tabular}


tumour necrosis factor- $a$, matrix metalloproteinases). The expression of these and other molecules, such as intercellular adhesion molecule 1, may trigger, in case of prolonged stimuli, the activation of adaptive immune pathways with lymphocytes migrating to the conjunctiva and eliciting a chronic immune-mediated inflammatory response. Corticosteroid treatment with high-medium potency molecules has been demonstrated to be effective but with significant, serious side effects; therefore, their long-term use is not recommended. The use of mild steroids, such as hydrocortisone, is highly indicated for patients with DED, where a longlasting anti-inflammatory treatment is advisable. ${ }^{34}$ This treatment can be considered safer than other types of corticosteroid molecules; however, it is always mandatory to check intraocular pressure and the lens status during the treatment.

Other molecules can be used to treat inflammation alone or in combination with corticosteroids. ${ }^{41-43}$ Omega-3 fatty acids, cyclosporine A, tacrolimus and lifitegrast have all been indicated as possible treatments acting on specific aspects of inflammation. Omega-3 is a useful supplement able to address some aspects of inflammation through the formation of potent antiinflammatory and pro-resolving lipid mediators. ${ }^{39} \quad 40 \quad 67 \quad 68$ A recent study has demonstrated that the use of eye drops containing n-3 eicosapentaenoic (EPA) and docosahexaenoic acids (DHA) has a positive effect on the entire ocular surface system and could be a complementary therapeutic strategy for the treatment of DED and photorefractive keratectomy. ${ }^{67}$

However, in a recent multicenter, double-masked clinical trial where moderate-to-severe DED patients were randomised to receive for 1 year, either a daily oral dose of EPA and DHA (treatment group) or olive oil (placebo group), there were no significant differences between the two groups for both the signs and symptoms of DED. ${ }^{69}$

Other molecules, including cyclosporine A, tacrolimus and lifitegrast act by inhibiting lymphocyte migration to the ocular surface but require a longer period compared to corticosteroids before they become effective in controlling inflammation. ${ }^{35-38} 65$

The correct use of tear substitutes can play an important role in helping to achieve the control of the inflammatory process on the ocular surface: they improve tear fluid clearance and reduce the concentration of pro-inflammatory agents. This is in contrast to punctal plugs, which are used to prolong the permanence of tears on the ocular surface by inhibiting their clearance. Consequently, the use of punctal plugs should be reserved for conditions in which inflammation of the ocular surface is not present or upon patient request in specific social occasions like celebrations or extensive video terminal use. In these situations, punctal plugs use should be limited to short time periods.

\section{Epithelial protection}

Another pillar of DED therapy is epithelium protection, necessary to interrupt the vicious circle that is sustained by proinflammatory cytokines produced during epithelial damage. The protective physical and biological characteristics of some tears have been identified as a potential treatment to protect epithelial damage (table 2). ${ }^{46-48}$ 70-88 Trehalose has been indicated as a possible therapeutic tool, able to interfere with the cellular metabolic dysfunction associated with DED and control inflammation. This naturally occurring sugar is a non-reducing disaccharide, found in high concentrations in many organisms, and is a key element involved in anhydrobiosis (ability to survive almost complete dehydration). Its presence also confers resistance to desiccation and high osmolarity in bacterial and human cells. ${ }^{79} 80$ Owing to these characteristics, trehalose was used to protect the amniotic membrane for ocular surface reconstruction during the process of preservation. ${ }^{80}$ In addition, it has been hypothesised that the ability of trehalose to effectively control inflammation is due to the activation of the transcription factor E-boxB/autophagy cellular degradation pathway, which seems to be involved in the maintenance of corneal homoeostasis and suppression of cell death during an apoptosis-inducing inflammatory insult. ${ }^{47488}$ It has been demonstrated that trehalose preserves the integrity of the cells and their intracellular organelles through multiple mechanisms, which are not yet fully understood. ${ }^{49} 89$

Hyaluronic acid is a strongly hydrophilic, non-sulfated, disaccharide, glycosaminoglycan, with a molecular weight ranging

Table 2 Topical treatment options for the control of ocular surface inflammation

\begin{tabular}{|c|c|c|}
\hline Drug & Characteristics & Author, year (Ref.) \\
\hline Corticosteroids & Fast action, highly effective, possible side effects, usually not for chronic use. & $\begin{array}{l}\text { Marsh, } 1999^{31} \\
\text { Pfulgfelder, 2004 } \\
\text { Aragona, } 2013^{33} \\
\text { Rolando, } 2017^{34}\end{array}$ \\
\hline Cyclosporine A & Acts on T lymphocyte recruitment, delayed achievement of full therapeutic effect. & $\begin{array}{l}\text { Sall, } 2000^{35} \\
\text { Leonardi, } 2016^{36}\end{array}$ \\
\hline Tacrolimus & Acts on T lymphocyte recruitment, delayed achievement of full therapeutic effect. & Moscovici, $2012^{37}$ \\
\hline Lifitegrast & Inhibits lymphocyte activation by blocking ICAM-1 and LFA-1 receptors. & Perez, $2016^{38}$ \\
\hline Omega-3 & $\begin{array}{l}\text { Reduces the activation of pro-inflammatory cytokines, increases anti-inflammatory prostagliandins, promotes the resolution } \\
\text { of inflammation (resolvins), improves nerve neuroprotection (neuroprotectins) }\end{array}$ & $\begin{array}{l}\text { Li, } 2010^{39} \\
\text { Cortina, } 2010^{40}\end{array}$ \\
\hline $\begin{array}{l}\text { Non-steroidal anti- } \\
\text { inflammatory drugs }\end{array}$ & $\begin{array}{l}\text { Mediate the breakdown of arachidonic acid cascade; side effects are decreased corneal sensitivity and sporadic corneal } \\
\text { melting; currently not strongly suggested. }\end{array}$ & $\begin{array}{l}\text { Rolando, } 2002^{41} \\
\text { Aragona, } 2000^{42} \\
\text { Aragona, } 2005^{43}\end{array}$ \\
\hline Doxycycline & Reduces MMP-9 expression, macrophage, interleukin $1 \beta$, interleukin 6 and TNF-alfa. & Zhang, $2014^{44}$ \\
\hline Azithromycin & Restores the levels of carotenoids in meibum and decreases signs and symptoms of DED. & Foulks, $2013^{45}$ \\
\hline Tear substitutes & $\begin{array}{l}\text { Increase tear fluid clearance, reduce concentration of pro-inflammatory factors. Osmoprotection and increase autophagy } \\
\text { (ie, trehalose) }\end{array}$ & $\begin{array}{l}\text { Baudouin, } 2013^{46} \\
\text { Uchida, 2014 } \\
\text { Sarkar, 2007 } \\
\text { Fariselli, } 2017^{49}\end{array}$ \\
\hline Nerve growth factor & Regenerates corneal nerve, improves tear secretion and epithelial cell turnover. & Coassin, $2005^{50}$ \\
\hline Autologous serum & Improve tear stability, fluorescein and rose bengal staining scores as well as subjective symptom scores & Kojima, $2005^{51}$ \\
\hline
\end{tabular}

DED, dry eye disease; ICAM-1, intercellular adhesion molecule 1; LFA-1, lymphocyte function-associated antigen 1; MMP-9, matrix metalloproteinase 9; TNF, tumour necrosis factor. 
from $<100$ to $>1000 \mathrm{kDa}$, occurring naturally in the human body. ${ }^{90} \mathrm{It}$ is currently considered an essential component in tear substitution formulations, where it increases viscosity, improves retention time, and optimises ocular surface hydration and lubrication. ${ }^{91-93}$ There are several formulations present on the market, particularly in Europe, which differ in concentration, molecular weight and viscosity, whereas in some products, additional components are added to sodium hyaluronate in order to address specific aspects of DED. ${ }^{29}$ Generally, viscous solutions may be useful to treat conditions where epithelial recovery is necessary, whereas less viscous eye drops are used when an increased tear clearance is required.

\section{Lid management}

For a complete ocular surface treatment, other aspects must be taken into account, most notably, the meibomian gland dysfunction (MGD)/blepharitis and nerve impairment.

To control MGD/blepharitis, several measures are necessary, including lid hygiene, by means of warm/hot compresses and medicated wipes, topical or systemic antibiotic treatments, antiinflammatory agents and less viscous tear substitutes for increasing tear clearance. MGD and blepharitis are the consequence of MG disease: this can be isolated but is more frequently associated with skin alterations, indicating a general sebaceous dysfunction. Rosacea is a chronic skin disorder that affects the facial skin and is characterised by transitory vasodilation, persistent telangiectasia with papules and pustules. It is frequently accompanied by severe MGD and blepharitis, potentially leading to corneal neovascularisation in more advanced stages. To treat this condition, both oral tetracyclines (eg, minocycline and doxycycline) and topical antiinflammatory treatments can be useful. ${ }^{44}{ }^{45} \mathrm{~A}$ tapering course of potent corticosteroids can be used and, once the response is obtained, the anti-inflammatory treatment can be continued with milder corticosteroids in a lower dosage for long-term use (table 3).

The use of medium-viscosity formulation tear substitutes to increase tear clearance and stabilise the tear film is an important consideration in treating MGD/blepharitis. The frequency of instillation should be consistent (four to six times a day), with the aim of controlling symptom presentation. The ancillary use of eye drops containing resolvins that are molecules derived from omega-3 polyunsaturated fatty acids, EPA and DHA is advisable (two to three times a day). Self-administered lid hygiene is mandatory and should be based on warm/hot compresses or heating goggles (Blephasteam) and medicated wipes. Recently, a new inoffice treatment has been developed to safely administer therapeutic levels of heat and pressure (LipiFlow), which has demonstrated a higher and more sustained improvement in reducing both the signs and symptoms of MGD compared to conventional warm/hot compresses. ${ }^{94}$ Subjects with lid margin problems should be informed that their disease is chronic and caused by structural alterations of MG, which can be treated to reduce episodic flare-ups but cannot be completely resolved. In case of worsening, the administration of more potent drugs should be considered, followed by tapering and returning to baseline treatments once the relapsing episode is under control.

Recently, the use of intense pulsed light has been suggested and documented by the literature as a possible treatment of MGD. ${ }^{95-97}$ However, further appropriately controlled studies are desirable to demonstrate that this method is more effective compared to correctly performed warm/hot compresses. Tolerance with this procedure may be an issue, with some patients reporting an increase in long-lasting ocular pain after the procedure, suggesting a possible interference with the sensitive nervous system. Furthermore, this method is not

Table 3 Protective physical and biological characteristics of tear substitutes

\begin{tabular}{|c|c|c|}
\hline Molecule & Characteristics & Author, year (Ref.) \\
\hline & Physical protection & \\
\hline Cellulose derivates & $\begin{array}{l}\text { Increase residence time and tear film volume. Good level of adhesion to epithelial cells, especially in } \\
\text { high concentration. }\end{array}$ & $\begin{array}{l}\text { Toda, } 1996^{70} \\
\text { Garrett, } 2007^{71}\end{array}$ \\
\hline Hydroxypropyl guar & Lubricates the interface between lids and bulbar surface reducing epithelial stress. & Rolando, $2009^{72}$ \\
\hline $\begin{array}{l}\text { Medium/high- molecular-weight and chain length } \\
\text { biopolymers (ie, sodium hyaluronate) }\end{array}$ & $\begin{array}{l}\text { Non-Newtonian viscoelastic activity. Allow for a good viscosity when the eye is open that suddenly } \\
\text { decreases during blinking, thus improving tear film thickness when the eyes are open and comfort } \\
\text { during eye closure. }\end{array}$ & $\begin{array}{l}\text { lester, } 2000^{73} \\
\text { Aragona, } 2002^{74} \\
\text { Aragona, } 2002^{75}\end{array}$ \\
\hline $\begin{array}{l}\text { High concentration polymers, complexed } \\
\text { biopolimers, carbomer gels }\end{array}$ & $\begin{array}{l}\text { Retain water in their structure so reducing the effect of lid friction and maintaining the volume of the } \\
\text { tear film. }\end{array}$ & $\begin{array}{l}\text { Garrett, } 2007^{71} \\
\text { Postorino, } 2017^{76} \\
\text { Cagini, } 2017^{77} \\
\text { Sullivan, } 1997^{78}\end{array}$ \\
\hline Membrane stabilisers & $\begin{array}{l}\text { Ectoin and trehalose stabilise lipid layers cells by the interaction between hydrocomplexes and lipids, } \\
\text { creating a protective and stabilising water shell. }\end{array}$ & Graf, $2008^{86}$ \\
\hline \multicolumn{3}{|c|}{ Biological protection } \\
\hline Sodium hyalunorate & $\begin{array}{l}\text { Reduces squamous metaplasia improving goblet cells expression and epithelial cells morphology; } \\
\text { improves cellular kinetics, binds to CD44, the specific receptor present in the cells. }\end{array}$ & $\begin{array}{l}\text { Entwistle, } 1996^{81} \\
\text { Lerner, } 1998^{82} \\
\text { Gomes, } 2004^{83} \\
\text { Aragona, } 2007^{84}\end{array}$ \\
\hline Compatible solutes & $\begin{array}{l}\text { Osmoprotection by antagonising cell dehydration protecting from denaturation of cellular proteins, } \\
\text { preventing cellular shape changes and apoptosis (carnitin, eritritol, trehalose, glycerin, betaine, etc). }\end{array}$ & $\begin{array}{l}\text { Baudouin, } 2013^{46} \\
\text { Aragona, } 2014^{85}\end{array}$ \\
\hline Vitamins, antioxidants, and fundamental ions & Influence metabolic activities of the cells improving cell viability & $\begin{array}{l}\text { Macrì, } 2015^{87} \\
\text { Uchida, } 2014^{47}\end{array}$ \\
\hline Trehalose & $\begin{array}{l}\text { Cell hydration maintainer; its presence confers desiccation resistance to bacterial and human cells; its } \\
\text { remarkable effectiveness is due to the ability to replace some of the water in the cell, thereby stabilising } \\
\text { and protecting the cellular membrane and proteins during the freezing process. } \\
\text { Autophagy promotion: cleaning of immunostimulating DNA fragments lowering the risk of adaptive } \\
\text { immune response. }\end{array}$ & $\begin{array}{l}\text { Guo, } 2000^{79} \\
\text { Nakamura, } 2008^{80} \\
\text { Ohsumi, } 2014^{88} \\
\text { Sarkar, } 2007^{48}\end{array}$ \\
\hline
\end{tabular}


indicated in subjects with skin prototype VI or very dark skin where the results are poor. ${ }^{95}$

\section{Nerve treatment}

The last pillar of DED is neurological impairment, which is responsible for the frequent lack of correlation between signs and symptoms in patients. There is still a lack of treatments able to address nerve structures, although human recombinant nerve growth factor (NGF) is now on the market for neurotrophic keratitis and is under investigation in the USA and Europe for DED treatment. ${ }^{50}$ Several substances have been suggested and are currently used to improve ocular surface sensation. Among these, omega-3 derivatives seem to play a significant role in nerve protection and regeneration, when used either alone or in combination with NGF or pigment epithelium-derived factor. ${ }^{98-101}$ The use of vitamin $\mathrm{B}_{12}$ has been proven in an animal model to improve both corneal epithelial healing and nerve regeneration, ${ }^{102}$ whereas sodium hyaluronate eyedrops containing vitamin $\mathrm{B}_{12}$ are commonly used for epithelial improvement. ${ }^{103}$ Other vitamins involved in ocular surface health are vitamins A and D used as oral supplements and vitamin A as a topical application, which have demonstrated an improvement in DED signs and symptoms. ${ }^{104-107}$ Amino acid-enriched tear substitutes have been proven to be effective in improving corneal nerve structure in patients with DED. ${ }^{108}$

Possible future developments will consider the use of biological drugs in the treatment of DED and associated conditions such as psoriasis. 109110

The goal of treatment should be to improve patients' signs and symptoms, while adapting the treatment is necessary in order to achieve good homoeostasis.

The relationship with the patient is also a crucial aspect of the treatment plan.

\section{DOCTOR AND PATIENT RELATIONSHIP}

Empathy and willingness to explain the disease with patients, who often fell isolated without much understanding and comprehension from both medical professionals and relatives, is an important part of the treatment process. Patients generally feel that their disease is impossible to treat, leading to noncompliance and discontinuation, which can perpetuate the vicious circle of ocular surface damage.

It is important that physicians explain that the disease is chronic, with the severity of signs and symptoms fluctuating depending on internal body circumstances and reactions to environmental conditions. Consequently, therapies will need to be monitored and adjusted if necessary. Critically, it needs to be stated that there will frequently be a time lag before any kind of improvement will occur, but that therapies will substantially improve their quality of life.

It is possible that the eyes will remain slightly more reactive to changes in the environment. Therefore, it should be explained that patients might need to modify the frequency and/or type of eye drops according to the change of symptoms, following a preplanned rescue prescription. In particular, patients should address a series of questions in order to self-monitor their condition, such as

- Do I feel that I need a more suitable treatment compared to last week?

- When I go outside?

- When performing visual tasks (TV, computer, reading, driving)?

- Am I feeling discomfort, heaviness or irritation in my eye?
If the patient responds to one or more of these questions with yes, it is reasonable to assume that the patient would need to increase the frequency of tear substitute instillation, enhancing/ starting anti-inflammatory treatment or possibly a new course of antibiotics.

It is also important to schedule follow-up visits to demonstrate that the physician is managing the patients' care and to discuss any issues with the treatment and adapt it if necessary. It is advisable, if the clinical conditions allow it, to initially schedule visits every 3 months, and then every 6 months. It is important to assure the patient that the physician will be ready to support them with any queries and schedule further visits if necessary.

In conclusion, dry eye is a multifactorial disease of the tears and the ocular surface, a system formed by several structures working together to protect the eye from excessive environmental and biological stress. It is therefore critical to treat the main pathogenic mechanism(s) involved in DED and to address also the secondary mechanisms that, if not appropriately controlled, might contribute to perpetuate the vicious circle of DED. A proper and adaptable treatment will improve the ocular surface inducing a relief from symptoms and an effective improvement of the quality of life.

Contributors PA, RM, PR, EC, MR designed and directed the project; all authors conceived the idea of the review; PA, GG, MR drafted the manuscript with input from all authors; RM, PR, EC provided critical feedback. All authors contributed to the final version of the manuscript.

Funding This paper was supported by an unrestricted grant from Théa Farma S.p.A. Competing interests None declared.

Provenance and peer review Not commissioned; externally peer reviewed.

Open access This is an open access article distributed in accordance with the Creative Commons Attribution Non Commercial (CC BY-NC 4.0) license, which permits others to distribute, remix, adapt, build upon this work non-commercially, and license their derivative works on different terms, provided the original work is properly cited, appropriate credit is given, any changes made indicated, and the use is noncommercial. See: http://creativecommons.org/licenses/by-nc/4.0/.

\section{ORCID iDs}

Pasquale Aragona http://orcid.org/0000-0002-9582-9799

Giuseppe Giannaccare http://orcid.org/0000-0003-2617-0289

Maurizio Rolando http://orcid.org/0000-0002-4982-1462

\section{REFERENCES}

1 Stapleton F, Alves M, Bunya VY, et al. TFOS DEWS II epidemiology report. Ocul Surf 2017;15:334-65.

2 Rolando $\mathrm{M}$, lester $\mathrm{M}$, Macrì $\mathrm{A}$, et al. Low spatial-contrast sensitivity in dry eyes. Cornea 1998;17:376-9.

3 Benitez-Del-Castillo J, Labetoulle M, Baudouin C. et al. Visual acuity and quality of life in dry eye disease: proceedings of the OCEAN group meeting. Ocul Surf 2017;15:169-78.

4 Uchino M, Schaumberg DA. Dry eye disease: impact on quality of life and vision. Curr Ophthalmol Rep 2013;1:51-7.

5 Wolffsohn JS, Arita R, Chalmers R, et al. TFOS DEWS II diagnostic methodology report. Ocul Surf 2017;15:539-74.

6 van Setten G, Labetoulle M, Baudouin C, et al. Evidence of seasonality and effects of psychrometry in dry eye disease. Acta Ophthalmol 2016;94:499-506.

7 Nichols KK, Redfern RL, Jacob JT, et al. The TFOS international workshop on contact lens discomfort: report of the definition and classification subcommittee. Invest Ophthalmol Vis Sci 2013;54:14-19.

8 Carnt NA, Keay L, Naduvilath T, et al. Risk factors associated with corneal inflammation in soft contact lens daily wear. Invest Ophthalmol Vis Sci 2007;49:4326.

9 Rolando M, Cantera E, Mencucci R, et al. The correct diagnosis and therapeutic management of tear dysfunction: recommendations of the P.I.C.A.S.S.O board. Int Ophthalmol 2018;38:875-95.

10 Baudouin C, Messmer EM, Aragona P, et al. Revisiting the vicious circle of dry eye disease: a focus on the pathophysiology of meibomian gland dysfunction. $\mathrm{Br}$ J Ophthalmol 2016;100:300-6.

11 Mantelli F, Argueso P. Functions of ocular surface mucins in health and disease. Curr Opin Allergy Clin Immunol 2008;8:477-83.

12 Craig JP, Tomlinson A. Importance of the lipid layer in human tear film stability and evaporation. Optom Vis Sci 1997;74:8-13. 
13 Rolando M, Refojo MF, Kenyon KR. Tear water evaporation and eye surface diseases. Ophthalmologica 1985;190:147-9.

14 Braun RJ, King-Smith PE, Begley CG, et al. Dynamics and function of the tear film in relation to the blink cycle. Prog Retin Eye Res 2015;45:132-64.

15 Stepp MA, Tadvalkar G, Hakt R, et al. Corneal epithelial cells function as surrogate Schwann cells for their sensory nerves. Glia 2017;65:851-63.

16 Aragona P, Rania L, Puzzolo D. The role of inflammation, inflammatory cytochines, and ocular surface markers in dry eye disease. In: Benitez Del Castillo JM, Lemp MA, eds. Ocular surface disorders. London: JP Medical Publishing, 2013:55-68.

17 Lemp MA, Baudouin C, Baum J. et al. The definition and classification of dry eye disease: report of the definition and classification subcommittee of the international dry eye workshop. Ocul Surf 2007;5:75-92.

18 Musumeci M, Bellin M, Maltese A, et al. Chitinase levels in the tears of subjects with ocular allergies. Cornea 2008;27:168-73.

19 Musumeci M, Aragona P, Bellin M, et al. Acidic mammalian chitinase in dry eye conditions. Cornea 2009;28:667-72.

20 Chen Z, Tong L, Li Z, et al. Hyperosmolarity-induced codification of human corneal epithelial cells is regulated by JNK MAPK. Invest Ophthalmol Vis Sci 2008:49:539-49.

21 Salomon A, Dursun D, Liu Z, et al. Pro- and anti-inflammatory forms of interleukin-1 in the tear fluid and conjunctiva of patients with dry eye disease. Invest Ophthalmol Vis Sci 2001:42:2283-92.

22 Massingale ML, Li X, Vallabhajosyula M, et al. Analysis of inflammatory cytokines in the tears of dry eye patients. Cornea 2009;28:1023-7.

23 Kang MH, Kim MK, Lee HJ, et al. Interleukin-17 in various ocular surface inflammatory diseases. J Korean Med Sci 2011;26:938-44.

24 De Paiva CS, Corrales RM, Villareal AL, et al. Corticosteroid and doxycycline suppress MMP-9 and inflammatory cytokine expression, MAPK activation in the corneal epithelium in experimental dry eye. Exp Eye Res 2006;83:526-35.

25 Brignole F, Pisella PJ, Goldschild M, et al. Flow cytometric analysis of inflammatory markers in conjunctival epithelial cells of patients with dry eye. Invest Ophthalmol Vis Sci 2000:41:1356-63.

26 Aragona P, Rolando M. Towards a dynamic customised therapy for ocular surface dysfunctions. Br J Ophthalmol 2013;97:955-60.

27 Zaki I, Fitzgerald P, Hardy JG, et al. A comparison of the effect of viscosity on the precorneal residence of solutions in rabbit and man. J Pharm Pharmacol 1986;38:463-6

28 Prabhasawat $\mathrm{P}$, Tseng SC. Frequent association of delayed tear clearance in ocular irritation. Br J Ophthalmol 1998;82:666-75.

29 Aragona P, Simmons PA, Wang $\mathrm{H}$, et al. Physicochemical properties of Hyaluronic acid-based lubricant eyedrops. Trans Vis Sci Technol 2019;8:2.

30 Tong L, Beuerman R, Simonyi S, et al. Effects of punctal occlusion on clinical signs and symptoms and on tear cytokine levels in patients with dry eye. Ocul Surf 2016;14:233-41.

31 Marsh P, Pflugfelder SC. Topical nonpreserved methylprednisolone therapy for keratoconjunctivitis sicca in Sjögren syndrome. Ophthalmology 1999:106:811-6.

32 Pflugfelder SC, Maskin SL, Anderson B, et al. A randomized, double-masked, placebo-controlled, multicenter comparison of loteprednol etabonate ophthalmic suspension, $0.5 \%$, and placebo for treatment of keratoconjunctivitis sicca in patients with delayed tear clearance. Am J Ophthalmol 2004;138:444-57.

33 Aragona P, Spinella R, Rania L, et al. Safety and efficacy of $0.1 \%$ clobetasone butyrate eyedrops in the treatment of dry eye in Sjögren syndrome. Eur J Ophthalmol 2013:23:368-76

34 Rolando M, Vagge A. Safety and efficacy of cortisol phosphate in hyaluronic acid vehicle in the treatment of dry eye in Sjogren Syndrome. J Ocul Pharmacol Ther 2017:33:383-90.

35 Sall K, Stevenson OD, Mundorf TK, et al. Two multicenter, randomized studies of the efficacy and safety of cyclosporine ophthalmic emulsion in moderate to severe dry eye diseaseCsA Phase 3 Study Group. Ophthalmology 2000;107:631-9.

36 Leonardi A, Van Setten G, Amrane M, et al. Efficacy and safety of $0.1 \%$ cyclosporine A cationic emulsion in the treatment of severe dry eye disease: a multicenter randomized trial. Eur J Ophthalmol 2016;26:287-96.

37 Moscovici BK, Holzchuh R, Chiacchio BB, et al. Clinical treatment of dry eye using 0.03\% tacrolimus eye drops. Cornea 2012;31:945-9.

38 Perez VL, Pflugfelder SC, Zhang S, et al. Lifitegrast, a novel integrin antagonist for treatment of dry eye disease. Ocul Surf 2016;14:207-15.

39 Li N, He J, Schwartz CE, et al. Resolvin E1 improves tear production and decreases inflammation in a dry eye mouse model. J Ocul Pharmacol Ther 2010;26:431-9.

40 Cortina MS, He J, Li N, et al. Neuroprotectin D1 synthesis and corneal nerve regeneration after experimental surgery and treatment with PEDF plus DHA. Invest Ophthalmol Vis Sci 2010;51:804-10.

41 Rolando M, Barabino S, Alongi S, et al. Topical non-preserved diclofenac therapy for keratoconjunctivitis sicca. Adv Exp Med Biol 2002;506:1237-40.

42 Aragona P, Stilo A, Ferreri F, et al. Effects of the topical treatment with NSAIDs on corneal sensitivity and ocular surface of Sjogren's syndrome patients. Eye (Lond) 2005;19:535-9.
43 Aragona P, Tripodi G, Spinella R, et al. The effects of the topical administration of non-steroidal anti-inflammatory drugs on corneal epithelium and corneal sensitivity in normal subjects. Eye (Lond) 2000;14:206-10.

44 Zhang Z, Yang WZ, Zhu ZZ, et al. Therapeutic effects of topical doxycycline in a benzalkonium chloride-induced mouse dry eye model. Invest Ophthalmol Vis Sci 2014;55:2963-74

45 Foulks GN, Borchman D, Yappert M, et al. Topical azithromycin and oral doxycycline therapy of meibomian gland dysfunction: a comparative clinical and spectroscopic pilot study. Cornea 2013;32:44-53.

46 Baudouin C, Aragona P, Messmer EM, et al. Role of hyperosmolarity in the pathogenesis and management of dry eye disease: proceedings of the OCEAN group meeting. Ocul Surf 2013;11:246-58.

47 Uchida K, Unuma K, Funakoshi T, et al. Activation of master autophagy regulator TFEB during systemic LPS administration in the cornea. J Toxicol Pathol 2014:27:153-8

48 Sarkar S, Davies JE, Huang Z, et al. Trehalose, a novel mTOR independent autophagy enhancer, accelerates the clearance of mutant huntingtin and alpha-synuclein. J Biol Chem 2007;282::5641-52.

49 Fariselli C, Giannaccare G, Fresina M, et al. Trehalose/hyaluronate eyedrops effects on ocular surface inflammatory markers and mucin expression in dry eye patients. Clin Ophthalmol 2018;12:1293-300

50 Coassin M, Lambiase A, Costa N, et al. Efficacy of topical nerve growth factor treatment in dogs affected by dry eye. Graefes Arch Clin Exp Ophthalmol 2005:243:151-5.

51 Kojima T, Ishida R, Dogru M, et al. The effect of autologous serum eyedrops in the treatment of severe dry eye disease: a prospective randomized case-control study. Am J Ophthalmol 2005;139:242-6.

52 Bartlett JD, Keith MS, Sudharshan L, et al. Associations between signs and symptoms of dry eye disease: a systematic review. Clin Ophthalmol 2015;9:1719-30.

53 Baudouin C, Aragona P, van Setten G, et al. ODISSEY European consensus group membersDiagnosing the severity of dry eye: a clear and practical algorithm. $\mathrm{Br}$ J Ophthalmol 2014;98:1168-76

54 Ross AR, Al-Aqaba MA, Almaazmi A, et al. Clinical and in vivo confocal microscopic features of neuropathic corneal pain. Br J Ophthalmol 2019; .

55 Mian SZ, Agranat JS, Jacobs D. SProsthetic replacement of the ocular surface ecosystem (PROSE) treatment for complications after LASIK. Eye Contact Lens 2016:42:371-3.

56 Giannaccare G, Versura P, Buzzi M, et al. Blood derived eye drops for the cornea and ocular surface diseases. Transfus Apher Sci 2017;56:595-604.

57 Giannaccare G, Buzzi M, Fresina M, et al. Efficacy of 2-month treatment with cord blood serum eye drops in ocular surface diseases: an in vivo confocal microscopy study. Cornea 2017;36:915-21.

58 Campos E, Versura $\mathrm{P}$, Buzzi $\mathrm{M}$, et al. Blood derived treatment from two allogeneic sources for severe dry eye associated to keratopathy: a multicentre randomised cross over clinical trial. Br J Ophthalmol 2019;

59 Aggarwal S, Colon C, Kheirkhah A, et al. Efficacy of autologous serum tears for treatment of neuropathic corneal pain. Ocul Surf 2019;17:532-9.

60 Goyal S, Hamrah P. Understanding neuropathic cornea pain gaps and current therapeutic approaches. Semin Ophthalmol 2016:31:59-70.

61 Sullivan DA, Rocha EM, Aragona P, et al. TFOS DEWS II sex, gender, and hormones report. Ocul Surf 2017;15:284-333.

62 Susarla R, Liu L, Walker EA, et al. Cortisol biosynthesis in the human ocular surface innate immune response. PLos One 2014;9:e94913.

63 Stevenson W, Chauhan SK, Dana R. Dry eye disease: an immune-mediated ocular surface disorder. Arch Ophthalmol 2012:130:90-100.

64 Barabino S, Chen YM, Chauhan S, et al. Ocular surface immunity: homeostatic mechanism and their disruption in dry eye disease. Progr Retin Eye Res 2012:31:271-85.

65 Aragona P. Topical cyclosporine: are all indications justified?. Br J Ophthalmol 2014:98:1001-2.

66 Aragona P, Aguennouz M, Rania L, et al. Matrix metalloproteinase 9 and transglutaminase 2 expression at the ocular in patients with different form of dry eye disease. Ophthalmology 2017;122:62-71

67 Barabino S, Horwath-Winter J, Messmer EM, et al. The role of systemic and topical fatty acids for dry eye treatment. Prog Retin Eye Res 2017;61:23-34.

68 Giannaccare G, Pellegrini M, Sebastiani S, et al. Efficacy of omega-3 fatty acid supplementation for treatment of dry eye disease: a meta-analysis of randomized clinical trials. Cornea 2019:38:565-73.

69 Asbell PA, Maguire MG, et al. Dry Eye Assessment and Management Study Research Group n-3 fatty acid supplementation for the treatment of dry eye disease. N Engl J Med 2018;378:1681-90

70 Toda I, Shinozaki N, Tsubota K. Hydroxypropyl methylcellulose for the treatment of severe dry eye associated with Sjögren's syndrome. Cornea 1996;15:120-8.

71 Garrett Q, Simmons PA, Xu S, et al. Carboxymethylcellulose binds to human corneal epithelial cells and is a modulator of corneal epithelial wound healing. Invest Ophthalmol Vis Sci 2007;48:1559-67.

72 Rolando M, Autori S, Badino F, et al. Protecting the ocular surface and improving the quality of life of dry eye patients: a study of the efficacy of an HP-guar containing 
ocular lubricant in a population of dry eye patients. J Ocul Pharmacol Ther 2009;25:271-8.

73 lester M, Orsoni GJ, Gamba G, et al. Improvement of the ocular surface using hypotonic $0.4 \%$ hyaluronic acid drops in keratoconjunctivitis sicca. Eye (Lond) 2000;14:892-8

74 Aragona P, Papa V, Micali A, et al. G. Long term treatment with sodium hyaluronate-containing artificial tears reduces ocular surface damage in patients with dry eye. Br J Ophthalmol 2002;86:181-4.

75 Aragona P, Di Stefano G, Ferreri F, et al. Sodium hyaluronate eye drops of different osmolarity for the treatment of dry eye in Sjögren's syndrome patients. $\mathrm{Br}$ J Ophthalmol 2002;86:879-84.

76 Postorino El, Rania L, Aragona E, et al. Efficacy of eyedrops containing cross-linked hyaluronic acid and coenzyme Q10 in treating patients with mild to moderate dry eye. Eur J Ophthalmol 2017;28:25-31.

77 Cagini C, Torroni G, Fiore T, et al. Tear film stability in Sjögren syndrome patients treated with hyaluronic acid versus crosslinked hyaluronic acid-based eye drops. J Ocul Pharmacol Ther 2017;33:539-42.

78 Sullivan LJ, McCurrach F, Lee S, et al. Efficacy and safety of $0.3 \%$ carbomer gel compared to placebo in patients with moderate-to-severe dry eye syndrome. Ophthalmology 1997;104::1402-8.

79 Guo N, Puhlev I, Brown DR, et al. Trehalose expression confers desiccation tolerance on human cells. Nat Biotechnol 2000;18:168-71.

80 Nakamura T, Sekiyama E, Takaoka M, et al. The use of trehalose-treated freeze-dried amniotic membrane for ocular surface reconstruction. Biomaterials 2008;29:3729-37.

81 Entwistle J, Hall CL, Turley EA. HA receptors: regulators of signalling to the cytoskeleton. J Cell Biochem 1996;61:569-77.

82 Lerner LE, Schwartz DM, Hwang DG, et al. Hyaluronan and CD44 in the human cornea and limbal conjunctiva. Exp Eye Res 1998;67::481-4.

83 Gomes JA, Amankwah R, Powell-Richards A, et al. Sodium hyaluronate (hyaluronic acid) promotes migration of human corneal epithelial cells in vitro. Br J Ophthalmol 2004;88::821-5.

84 Aragona P, Micali A, Paladino G, et al. Effects of tear substitutes on conjunctival epithelium of mice. Ophthalmic Res 2007;39::265-75.

85 Aragona $\mathrm{P}$, Colosi $\mathrm{P}$, Rania $\mathrm{L}$, et al. Protective effects of trehalose on the corneal epithelial cells. ScientificWorldJournal 2014;2014:717835.

86 Graf R, Anzali S, Buenger J, et al. The multifunctional role of ectoine as a natural cell protectant. Clin Dermatol 2008;26:326-33.

87 Macrì G, Scanarotti C, Bassi AM, et al. Evaluation of oxidative stress levels in the conjunctival epithelium of patients with or without dry eye, and dry eye patients treated with preservative-free hyaluronic acid $0.15 \%$ and vitamin B12 eye drops. Graefes Arch Clin Exp Ophthalmol 2015;253:425-30.

88 Ohsumi Y. Historical landmarks of autophagy research. Cell Res 2014; 24:9-23.

89 Matsuo T. Trehalose protects corneal epithelial cells from death by drying. $\mathrm{Br}$ J Ophthalmol 2001;85:610-2.

90 Fakhari A, Berkland CApplications and emerging trends of hyaluronic acid in tissue engineering, as a dermal filler and in osteoarthritis treatment. Acta Biomater 2013:9:7081-92.
91 Aragona P. Hyaluronan in the treatment of ocular surface disorders. In: Garg HG, Halse CA, eds. Chemistry and biology of hyaluronan. Elsevier Ltd., 2004:529-51.

92 Dogru M, Tsubota K. Pharmacotherapy of dry eye. Expert Opin Pharmacother 2011;12:325-34.

93 Laugh JR, Nguyen AL, Ketelson HA, et al. Precorneal residence time of artificial tears measured in dry eye subjects. Optom Vis Sci 2008;85:725-31.

94 Lane SS, DuBiner HB, Epstein RJ, et al. A new system, the LipiFlow, for the treatment of meibomian gland dysfunction. Cornea 2012;31:396-404.

95 Giannaccare G, Taroni L, Senni C, et al. Intense pulsed light therapy in the treatment of meibomian gland dysfunction: current perspectives. Clin Optom (Auckl) 2019:11:113-26.

96 Arita R, Mizoguchi T, Fukuoka S, et al. Multicenter study of intense pulsed light therapy for patients with refractory meibomian gland dysfunction. Cornea 2018;37:1566-71

97 Xue AL, Wang MTM, Ormonde SE, et al. Randomised double-masked placebo-controlled trail of the cumulative treatment efficacy profile of intense pulsed light therapy for meibomian gland dysfunction. Ocul Surf 2020;

98 He J, Bazan H. EPOmega-3 fatty acids in dry eye and corneal nerve regeneration after refractive surgery. Prostaglandins Leukot Essent Fatty Acids 2010;82:319-25.

99 He J, Pham TL, Kakazu A, et al. Recovery of corneal sensitivity and increase in nerve density and wound healing in diabetic mice after PEDF plus DHA treatment. Diabetes 2017:66:2511-20.

100 He J, Cortina MS, Kakazu A, et al. The PDEF neuroprotective domain plus DHA induces corneal nerve regeneration after experimental surgery. Invest Ophthalmol Vis Sci 2015;56:3505-13.

101 Zhang Z, Hu X, Qi X, et al. Resolvin D1 promotes corneal epithelial wound healing and restoration of mechanical sensation in diabetic mice. Mol Vis 2018;24:274-85.

102 Romano MR, Biagioni F, Carizzo A, et al. Effects of vitamin B12 on the corneal nerve regeneration in rats. Exp Eye Res 2014;120:109-17.

103 Versura P, Profazio V, Giannaccare G, et al. Discomfort symptoms reduction and ocular surface parameters recovery with Artelac Rebalance treatment in mild-moderate dry eye. Eur J Ophthalmol 2013;23:488-95.

104 Kim EC, Choi JS, Joo CK. A comparison of vitamin A and cyclosporine A $0.05 \%$ eye drops for treatment of dry eye syndrome. Am J Ophthalmol 2009;147:206-13.

105 Alanazi SA, El-Hiti GA, Al-Baloud AA, et al. Effects of short-term oral vitamin A supplementation on the ocular tear film in patients with dry eye. Clin Ophthalmol 2019:13:599-604.

106 Giannaccare G, Lucisano A, Pellegrini M, et al. Sterile corneal perforation occurring several years after biliopancreatic diversion. Obes Surg 2020;30:2847-50

107 Yang CH, Albietz J, Harkin DG, et al. Impact of oral vitamin D supplementation on the ocular surface in people with dry eye and/or low serum vitamin D. Cont Lens Anterior Eye 2018;41:69-76.

108 Aragona P, Rania L, Roszkowska AM, et al. Effects of amino acids enriched tear substitutes on the cornea of patients with dysfunctional tear syndrome. Acta Ophthalmol 2013;91:e437-44.

109 Aragona E, Rania L, Postorino El, et al. Tear film and ocular surface assessment in psoriasis. Br J Ophthalmol 2018;102:302-8.

110 Bartolotta A, Postorino E, Aragona E, et al. Secukinumab for plaque psoriasis with ocular comorbidity: a clinical experience. J Dermatolog Treat 2018;29:9-11. 